\title{
A Review on 4, 5-Imidazoledicarboxylic Acid: Their Chemistry and Coordination Potentials
}

\section{Worku Batu Dirersa*}

Department of Chemistry, Ambo University, Oromia, Ethiopia

\begin{abstract}
As part of heterocyclic imidazole interest to explore new receptors for anion; 4,5-imidazoledicarboxylic acid and their derivatives have great roles in coordination chemistry. This review, was also update the application and behaviour of 4,5-imidazoledicarboxylic acid $\left(\mathrm{H}_{3} \mathrm{IMDC}\right)$ as a potential motif for coordination compound in supramolecular structure activity. $\mathrm{H}_{3}$ IMDC contains one imidazole $\mathrm{NH}$ and two $\mathrm{COOH}$ protons which could be donated for hydrogen bonding to the anions. Due to the electronic properties of carboxyl group oxygens, coordination to metal ions can occur in different modes. In situ ligand synthesis is of growing interest as a new approach for the synthesis of coordination polymers. The main reason for interesting of 4,5-imidazoledicarboxylic acid $\left(\mathrm{H}_{3} \mathrm{IMDC}\right)$ and its derivatives in coordination polymers of metal-organic framework is because it has six potential donor atoms: two imidazole nitrogens and four carboxylate oxygen atoms, and can remove one to three hydrogen atoms forming $H_{3-n} I M D C^{n-}(n=1,2$ or 3$)$ species. The six donors may show various coordination modes and construct beautiful structures. In present review, the chemistry of 4,5-imidazoledicarboxylic acid and its coordination potential in coordination and supramolecular chemistry, which are uses as input for medicinal and drug synthesis, pharmacological actions and as biological activity; where reviewed based on the coordination potentials of imidazole derived heterocyclic molecules in metal-organic frameworks.
\end{abstract}

Keywords: Azole; Imidazole; 4, 5-Imidazoledicarboxylic acid; Coordination; Supramolecular chemistry

\section{Introduction}

\section{Heterocyclic compound of azole and imidazole}

A heterocyclic compound is a cyclic compound which has atoms of carbon and at least one or more donor heteroatom, such as nitrogen, oxygen and sulfur elements are as members of ring [1,2]. The chemistry of heterocyclic compounds is a logical as that of aliphatic or aromatic compounds. Heterocyclic compounds occur widely in nature and in a variety of non-naturally occurring compounds. Various compounds such as alkaloids, antibiotics, essential amino acids, the vitamins, hemoglobin, the hormones and a large number of synthetic drugs and dyes contain heterocyclic ring systems [3,4]. Example, among the different heterocyclic system, the chemistry of five member heterocyclic with more than one heteroatom has gained significance as many of them exhibit pronounced bioactive nature. One such type of compounds includes imidazole, isoxazolines, isoxazolidines and pyrazoline [1-5].

\section{Imidazole}

Imidazole (1, 3-diaza-2, 4-cyclopentadiene) is a planar five-member ring system with $3 \mathrm{C}$ and $2 \mathrm{~N}$ atom in 1 and 3 positions. The simplest member of the imidazole family is imidazole itself, a compound with molecular formula $\mathrm{C}_{3} \mathrm{H}_{4} \mathrm{~N}_{2}$ (Scheme 1). The systemic name for the compound is 1, 3 diazole, one of the annular $\mathrm{N}$ bear a $\mathrm{H}$ atom and can be regarded as a pyrole type $\mathrm{N}$. It is soluble in water and other polar solvents. It exists in two equivalent tautomeric forms because the hydrogen atom can be located on either of the two nitrogen atoms. Imidazole is a highly polar compound, as evidenced by a calculated dipole of 3.61D, and is entirely soluble in water [6]. The compound is classified as aromatic due to the presence of a sextet of $\pi$-electrons, consisting of a pair of electrons from the protonated nitrogen atom and one from each of the remaining four atoms of the ring. Imidazole is amphoteric, i.e., it can function as both an acid and as a base (Figure 1). As an acid, the pKa of imidazole is 14.5 , making it less acidic than carboxylic acids, phenols, and imides, but slightly more acidic than alcohols [6]. Imidazole derivatives of carboxylic acids or their derivatives can be obtained in good yields by reacting heterocyclic compounds having an aromatic structure, with at least two nitrogen atoms in the ring and at least one hydrogen atom on the ring, with carbon dioxide at elevated temperature in the presence of an acid binding reagent [7-9]. 4,5-Imidazoledicarboxylicacid is a useful intermediate for drugs. The amides which can be readily obtained from 4,5 -imidazoledicarboxylic acid have a stimulating effect on the central nervous system and are also used therapeutically as sedatives. 4, 5-Imidazoledicarboxylic acid is also used for the preparation of 4-aminoimidazole-5-carboxylic acid, an intermediate for purine syntheses, and is furthermore an important building block for semi-synthetic penicillin's and cephalosporins with excellent activity [7]. The background of ligand is relate to the novel Imidazoledicarboxylic acids derivatives, which are useful as antibiotics,

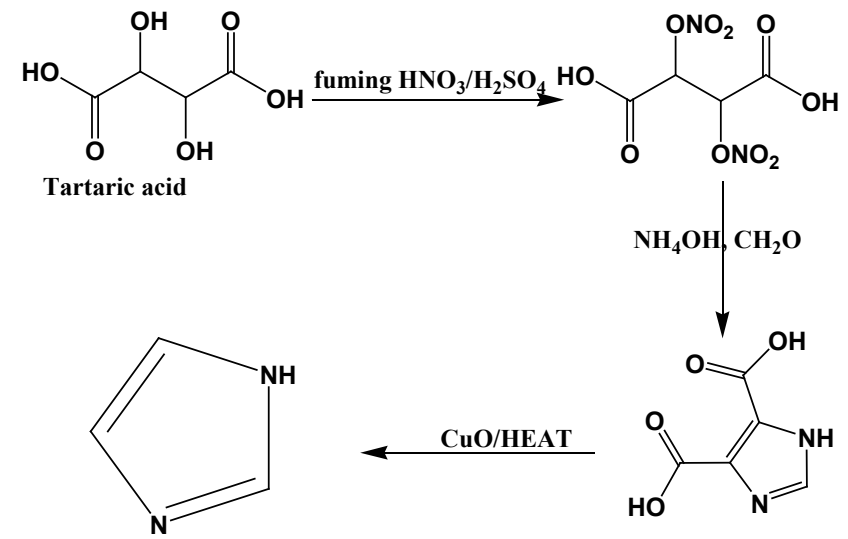

Scheme 1: Preparation of 4,5-imidazoledicarboxylic Acid from tartaric acid and Dinitrate.

*Corresponding author: Worku Batu Dirersa, Department of Chemistry, Ambo University, Oromia, Ethiopia, Tel: +251920231043; E-mail: worku.ebo21@gmail.com

Received June 13, 2017; Accepted June 21, 2017; Published June 23, 2017

Citation: Dirersa WB (2017) A Review on 4, 5-Imidazoledicarboxylic Acid: Their Chemistry and Coordination Potentials. Mod Chem appl 5: 222. doi: 10.4172/23296798.1000222

Copyright: (C) 2017 Dirersa WB. This is an open-access article distributed under the terms of the Creative Commons Attribution License, which permits unrestricted use, distribution, and reproduction in any medium, provided the original author and source are credited. 
particularly antibacterial agents in the treatment of infectious diseases caused by pseudomonas aeruginosa in both human beings and other animals and inter-mediates [7]. 4,5-Imidazoledicarboxylic acids is a bis-bidentate bridging ligand, having two nitrogen and two carboxyl groups and can act both as a multiple proton donor and acceptor as well as, highly accessible to metal ions to build interesting crystals structures $[10,11]$. A lot of fascinating complexes with 4, 5-imidazoledicarboxylate, pyrazine-2, 4-dicarboxylate, and its derivatives ligands which has $\mathrm{N}$, O-ligand can be used for supramolecular formation, because of their flexible coordination modes [11]. 4, 5-Imidazoledicarboxylic acid can be prepared by reaction tartaric acid dinitrate with ammonia and formaldehyde in aqueous solution [12]. This acid can also be obtained by oxidation of benzimidazole with potassium dichromate or potassium permanganate [13]. Preparation and subsequent dichromate oxidation of benzimidazole $\left(\mathrm{X}_{1}\right)$ and 2-methyl benzimidazole $\left(\mathrm{X}_{2}\right)$ are repeated and after certain modifications of the oxidation reactions, the products, 4,5-imidazoledicarboxylic acid $\left(\mathrm{X}_{1}^{\prime}\right)$ and 2-methylimidazole-4,5 dicarboxylic acid $\left(\mathrm{X}_{2}^{\prime}\right)$ are isolated according to Scheme 2 [13]. Compound of 2-phenylbenzimidazole on oxidation with acid dichromate yielded 2-phenyl-4, 5-imidazoledicarboxylic acid. in four percent yield as a reaction in Scheme 3 [13].

\section{4, 5-Imidazoledicarboxylic acid for synthesis of semi-syn- thetic penicillins}

The reaction of 4,5-imidazoledicarboxylic acid (I) with $\mathrm{SOCl}_{2}$ in refluxing benzene gives the corresponding acid chloride (II), which is condensed with 7-beta-[D-(-)-alpha amino phenyl acetamido] cephalosporanic acid sodium salt (III) by means of triethylamine in dichloromethane to afford 7-beta-[D-(-)-alpha[4(5)-carboxyimidazole-5(4)-carboxamido]phenyl acetamidol

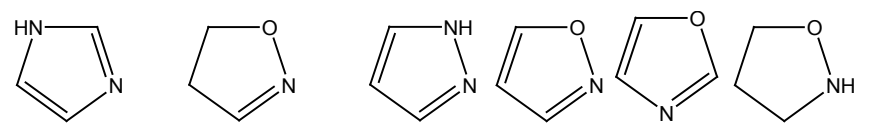
imidazole 4,5-dihydro-isoxazole $1 \mathrm{H}$-pyrazole isoxazole oxazole isoxazolidine<smiles>c1ccc2oncc2c1</smiles><smiles>Nn1cnnc1S</smiles><smiles>C1=NNCC1</smiles>

benzo(d)isoxazole 4-amino-4H-[1,2,4]triazole-3-thiol 4,5-dihydro-1H-pyrazole

Figure 1: Five Cyclic Ring of Azole Structure.<smiles>[R]c1nc2ccccc2[nH]1</smiles><smiles>[R]c1nc(C(=O)O)c([Y20]([Y4])([H])C)[nH]1</smiles>

Scheme 2: Five Cyclic Ring of Azole Structure.
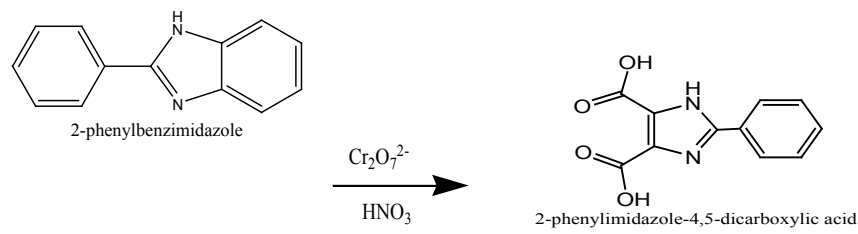

Scheme 3: Oxidation of 2-Phenylbenzimidazole by potassium dichromate. cephalon sporanic acid (IV). Finally, this compound is condensed with 4-pyridineethanesulfonic acid by means of $\mathrm{NaI}$ in water at $70^{\circ} \mathrm{C}$ [7-9]. Application of 4, 5-imidazoledicarboxylic acid with $\mathrm{SOCl}_{2}$ for Synthesis of semi-synthetic penicillin's (Figures 2 and 3 ).

\section{Supramolecular and coordination chemistry of 4, 5-imidaz- oledicarboxylic acid}

Imidazole refers to the class of simple aromatic ring organic compounds of the heterocyclic diazole series characterized by a 5-membered ring structure composed of three carbon atoms and two nitrogen atoms in adjacent positions [13]. 4, 5-Imidazoledicarboxylic acid is a multifunctional ligand and has potential coordination sites involving both nitrogen atoms of the imidazole ring and all of the carboxylate oxygen atoms. This ligand possesses three different protonated hydrogen's ( $\mathrm{Ha}, \mathrm{Hb}$ and $\mathrm{Hc}$ in Figure 4). Although both $\mathrm{Ha}$ and $\mathrm{Hb}$ are attached to carboxylic oxygen atoms, the two experience quite different coordination environments. The $\mathrm{Hc}$ in this ligand is linked to a nitrogen atom, and is more difficult to deprotonation than the other two hydrogen atoms. The difference in the binding power of these protons allows us to deprotonate them at different $\mathrm{pH}$ levels. The flexible, multifunctional coordination sites of this ligand also give a high likelihood for generation of coordination polymers with high dimensions. its functional groups (carboxylate and pyrazole ring) bind to metals selectively. But the bis-chelating of 4, 5-imidazoledicarboxylic acids have not been attempted for studies on first row transition metal complexation (Scheme 4). The nature of aromaticity on the ring of imidazole, conjugated $\mathrm{C}=\mathrm{N}$ and azomethine functional group of imidazole are grafted to achieve bis-multi identity towards metal ions. Therefore, the aim of this review paper was to contribute and initiate the researcher towards the new 4, 5-imidazoledicarboxylic acids based metal complex synthesis and characterization. Supramolecular chemistry and metal-organic polymeric networks via crystals engineering have produced many new complexes with unique structures [14-21]. The rational design and synthesis of novel Supramolecular complexes has recently attracted much attention, because of their intriguing structures and their various potential applications in catalysis, magnetism, photoluminescence, adsorption, gas storage, biological application, pharmaceutical activity, drugs, etc. $[16,14,20]$. The discrete metal-organic polygons and polyhedral have been widely studied and continue to be one of the most interesting. Particularly, the zero- dimensional unit with suitable hydrogen- bond donor and

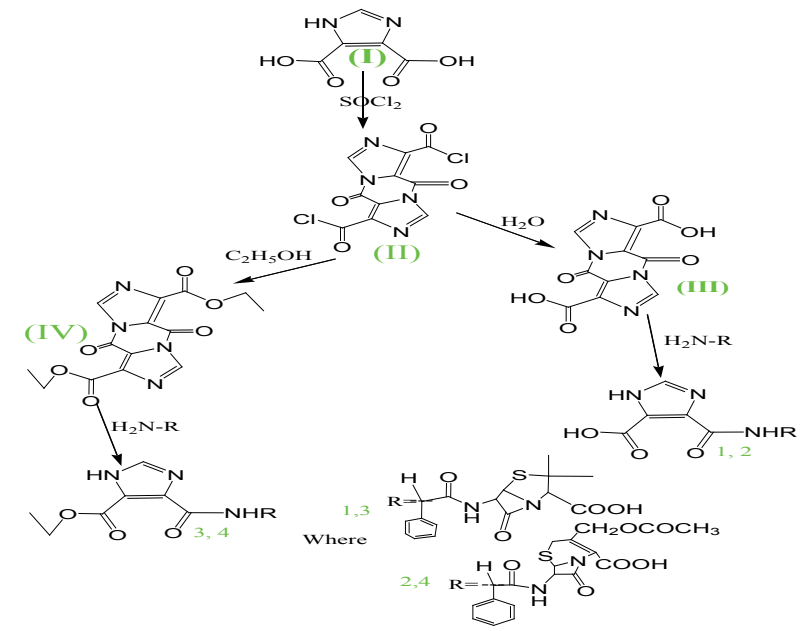

Scheme 4: 4, 5-Imidazoledicarboxylic Acid for Synthesis of Semi-Synthetic Penicillin's. 


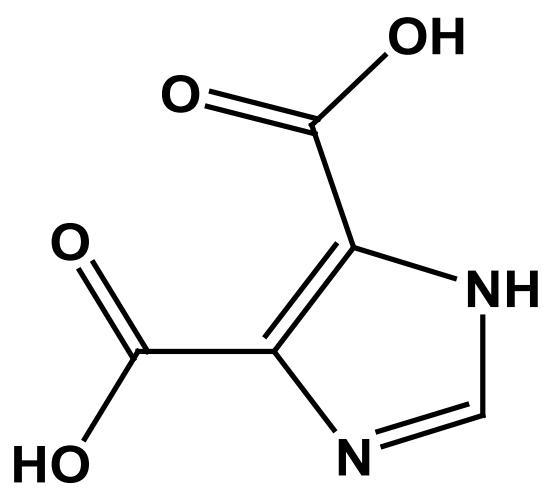

Figure 2: Imidazole.

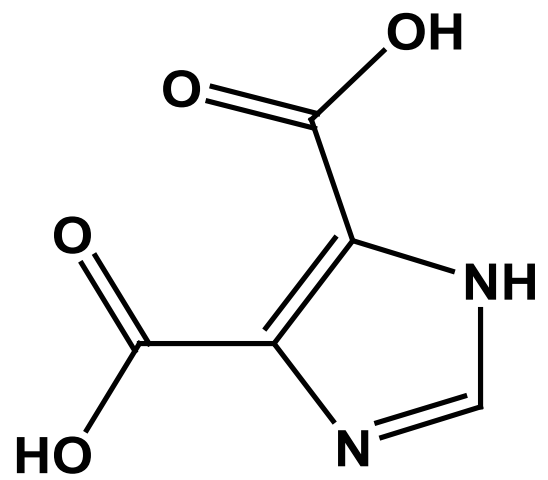

Figure 3: 4, 5-Imidazoledicarboxylic acid.

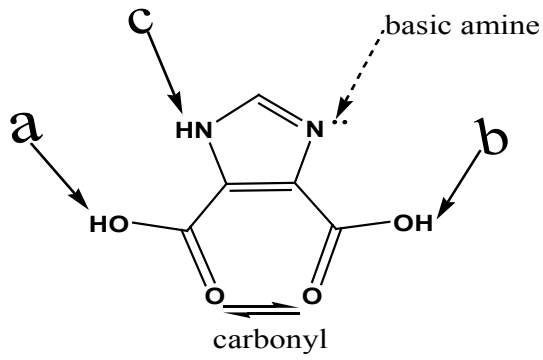

Figure 4: Structure of 4, 5-Imidazoledicarboxylic acid.

accept groups is important [11]. The structural modify of metal-organic frameworks are closely related to the geometry around the metal centers and organic ligand properties (Figures 5 and 6). The types of organic ligands containing $\mathrm{N}$ and $\mathrm{O}$-donors offer great potential for fine control over the coordination architectures of metal-organic frameworks (MOFs)due to their flexible coordination modes [10-18,20]. The selfassembly process of coordination polymers is frequently influenced by various factors such as medium, $\mathrm{pH}$ value of solution, temperature, the nature of metal ions, coordination arrangement, stereochemistry, and number of coordination donors provided by organic ligands $[17,18]$. Insight into the self-assembly process can be obtained by carrying out systematic studies under completely similar reaction conditions, while imposing subtle alterations such as changing the anions, the crystallization solvent, $\mathrm{pH}$ value of solution, or substituent groups of organic ligands, etc. These strategies undoubtedly help to shed light on the prediction, design, and synthesis of the target complexes. For example, imidazole-4,5-dicarboxylic acid ( $\left.\mathrm{H}_{3} \mathrm{IDC}\right)$, which can be partially or fully deprotonated to generate $\mathrm{H}_{2} \mathrm{IDC}^{-1}$, HIDC ${ }^{2-}$, and IDC $^{3-}$ anions at different $\mathrm{pH}$ values, coordinating with metal ions to form different Metal-Organic Frameworks with interesting 0-D, $1-\mathrm{D}, 2-\mathrm{D}$, and 3-D topologies $[16,18,20]$. Over the past few years, extensive investigation has focused on the construction of coordination polymers using 4,5-imidazoledicarboxylic acid as bridges of interest for the following reasons: (1) they are especially good multidentate $\mathrm{N}$ - or $\mathrm{O}$-donors with various coordination modes to metal ions and the ability to act as H-bond acceptors and donors to assemble various supramolecular structures; (2) they can be partly or fully deprotonated dependent on the $\mathrm{pH}$, providing various acid-base type coordination modes; (3) the two nitrogen's in the imidazole ring can orient the coordination, consistent with $\mathrm{Si}-\mathrm{O}-\mathrm{Si}$ bond angles in zeolites or $\mathrm{M}-$ IM-M bond angle in zeolitic imidazolate frameworks (ZIF) [16,18-20]. As a derivative of 2-methyl-imidazole-4, 5-dicarboxylic acid ( $\left.\mathrm{H}_{3} \mathrm{MIDC}\right)$ is similar with $\mathrm{H}_{3}$ IDC. More recently, analogues of $\mathrm{H}_{3}$ IDC such as 2-methyl-1H-imidazole-4,5-dicarboxylic acid, 2-ethyl-1H-imidazole4,5-dicarboxylic acid, 2-propyl-1H-imidazole-4,5-dicarboxylic acid, phenyl-4,5-imidazole dicarboxylic acid and 2-pyridyl-1H-imidazole4,5-dicarboxylic acid have been used to build up intriguing complexes as 1-D chains and ladders, 2-D grids, 3-D networks, and helical staircase networks under different conditions [16,18-20].

\section{Transition metal complexes of 4, 5-imidazoledicarboxylic acid in coordination chemistry}

Transition metal complexes is species consiting of a transition metal coordinated (bonded) to one or more ligands which are either neutral or anionic non-metal species. These transition metal ions usually form complexes with a well defined number of ligands [10-20]. Transition metal complexes containing imidazole heterocyclic compounds have<smiles></smiles>

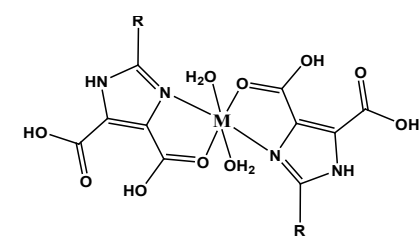

Figure 5: N, O-donor site of 4, 5-imidazodicarboxylic acid towards metal ion (M)<smiles>COC(=O)c1nc[nH]c1C(=O)O</smiles>

(a)
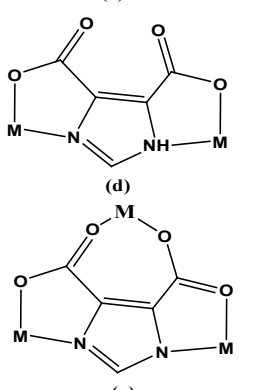

(g)<smiles></smiles>

(b)

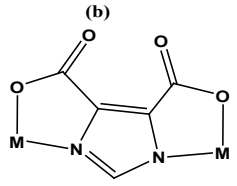

(e)

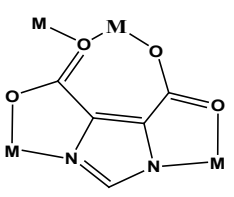<smiles></smiles>

(c)

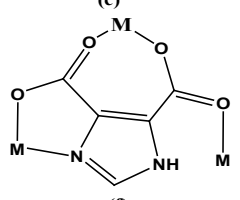

(f)

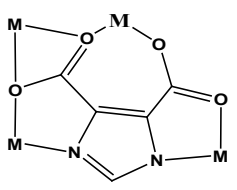

Figure 6: Coordination site and donor ability 4,5-imidazole-dicarboxylic acid (carboxylate) [16-21]. 
been of considerable interest in terms of structural chemistry, catalysis and biological functions. The chemical transformation of organic substance coordinated to transition metal ions are important as these provide facile synthesis of many novel molecules, that are otherwise difficult or even impossible to synthesize by conventional synthetic procedure [10-20]. During the past five years, increasing investigation has focused on the construction of coordination polymers using 4, 5-imidazoledicarboxylic acid as a ligand; it can coordinate with metal ions in many ways, resulting in the formation of MOFs with different topologies.

\section{Zinc complexes of imidazoledicarboxylates and pyridine-2, 5-dicarboxylic acid}

The reaction of heterocyclic dicarboxylic acids, such as pyridine2,5-dicarboxylic acid and imidazole-4,5-dicarboxylic acid, under hydrothermal conditions in the presence of an appropriate zinc salt yields three new zinc coordination polymers $\left[\left\{\mathrm{Zn}_{2}\left(\mathrm{H}_{2} \mathrm{O}\right)_{4}\right\}\right.$ $\left.\left\{\mathrm{C}_{5} \mathrm{H}_{3} \mathrm{~N}(\mathrm{COO})_{2}\right\}_{2}\right], \quad\left[\left\{\mathrm{Zn}\left(\mathrm{C}_{12} \mathrm{H}_{8} \mathrm{~N}_{2}\right)\right\}-\left\{\mathrm{C}_{5} \mathrm{H}_{3} \mathrm{~N}(\mathrm{COO})_{2}\right\} \cdot 0.5 \mathrm{H}_{2} \mathrm{O}\right], \quad$ and $\left[\left\{\mathrm{Zn}\left(\mathrm{C}_{12} \mathrm{H}_{8} \mathrm{~N}_{2}\right)\right\}\left\{\mathrm{C}_{3} \mathrm{HN}_{2}-(\mathrm{COO})_{2}\right\}\right]$. While later one forms with a zerodimensional molecular rectangular box structure, the second and third one have zigzag one-dimensional chain structures. The $\mathrm{Zn}^{2+}$ ions are coordinated by both the carboxylate oxygen atoms and also by the nitrogen atoms of the heterocycles [21-24]. Treatment of two kinds of Imidazoledicarboxylates ligands, 2-methyl- $1 \mathrm{H}$-imidazole-4,5dicarboxylic acid or 2-ethyl-1 $\mathrm{H}$-imidazole-4,5-dicarboxylic acid with $\mathrm{ZnSO}_{4}$, or $\mathrm{ZnCl}_{2}$, resulted in two supramolecular complexes, namely [Zn(2-methyl-1H-imidazole-4,5-dicarboxylate $\left.)_{2}\left(\mathrm{H}_{2} \mathrm{O}\right)_{2}\right]$ and $\{[\mathrm{Zn}(2$ ethyl-1H-imidazole-4,5 carboxylate $\left.\left.)_{2}\left(\mathrm{H}_{2} \mathrm{O}\right)_{2}\right] \cdot 3 \mathrm{H}_{2} \mathrm{O}\right\}$. Molecular structures of the two complexes have been characterized by means of elemental analysis, IR, and single crystal X-ray diffraction. Their thermal behaviors have also been presented [25].

\section{Silver, copper and potassium complexes of imidazoledicar- boxylates}

Four complexes, $\left.\left[\mathrm{Ag}_{4} \text { (bipy) }\right)_{2}(\mathrm{HIMDC})_{2}\left(\mathrm{H}_{2} \mathrm{O}\right)_{2}\right]_{\mathrm{n}},\left[\mathrm{Ag}\left(\mathrm{H}_{2} \mathrm{IMDC}\right)\right]_{\mathrm{n}}$, $\left[\mathrm{K}\left(\mathrm{H}_{3} \mathrm{IMDC}\right)\left(\mathrm{H}_{2} \mathrm{IMDC}\right)\left(\mathrm{H}_{2} \mathrm{O}\right)_{2}\right]_{\mathrm{n}}$, and $\left[\mathrm{Cu}(\mathrm{HIMDC})_{2}\right]\left(\mathrm{H}_{3} \mathrm{IMDC}=1 \mathrm{H}-\right.$ imidazole-4,5-dicarboxylic acid, $\mathrm{H}_{2} \mathrm{IMC}=1 \mathrm{H}$-imidazole-2-carboxylic acid, and bipy=4, 4-bipyridine), were hydrothermally synthesized and characterized by single-crystal X-ray diffraction analysis and elemental analyzed [16]. The obtained complexes exhibit different coordination structures; while silver complexes contains a 2-D supramolecular layer based on two chains arraying uniformly in an $\mathrm{ABAB}$ manner reported [16].

\section{Cobalt and nickel complexes of imidazoledicarboxylates}

Two complexes, $\left[\mathrm{Co}\left(\mathrm{H}_{2} \text { pimdc }\right)_{2}\left(\mathrm{H}_{2} \mathrm{O}\right)_{2}\right] .2 \mathrm{DMF}$ and $\left[\mathrm{Co}\left(\mathrm{H}_{2} \text { pimc }\right)_{2}\left(\mathrm{H}_{2} \mathrm{O}\right)_{2}\right] .4 \mathrm{H}_{2} \mathrm{O}$, have been designed, synthesized, and characterized (X-ray single crystal analysis, thermal analysis, electrochemical analysis, and infrared spectrum) based on the imidazole ligand $\left[\mathrm{H}_{3}\right.$ pimdc=2-propyl-4,5-imidazoledicarboxylic acid] [10]. Both compounds have 3-D hydrogen-bonding networks. Because of different coordination of water, forms a layer-like geometry via hydrogen bonds and forms a fishing net-like latticed geometry via hydrogen bonds [10]. Three new complexes, namely, $\left[\mathrm{Ni}(\mathrm{L})_{2} \cdot 2 \mathrm{H}_{2} \mathrm{O}\right] \cdot 3 \mathrm{H}_{2} \mathrm{O},\left[\mathrm{Co}(\mathrm{L})_{2} \cdot 2 \mathrm{H}_{2} \mathrm{O}\right]$ and $\left[\mathrm{Co}\left(\mathrm{L}^{\prime}\right)_{2} \cdot 2 \mathrm{H}_{2} \mathrm{O}\right](\mathrm{L}=2$-propyl-1H-imidazole-4,5-dicarboxylate and L'=2-methyl-1H-imidazole-4,5-dicarboxylate), were synthesized under hydrothermal conditions. X-ray diffraction analysis revealed that these complexes have zero-dimensional (0D) structures, which are extended into different multi-dimensional structures through hydrogen-bonding interactions [11]. Their crystal structures were further characterized by elemental analysis, IR spectroscopy, and thermo gravimetric analyses [11].

\section{Mixed ligand ruthenium and osmium complexes of imidaz- oledicarboxylates}

Mixed-ligand monometallic ruthenium (II) and osmium (II) complexes of composition $\left[(\text { bipy })_{2} \mathrm{M}\left(\mathrm{H}_{2} \mathrm{Imdc}\right)\right]\left(\mathrm{ClO}_{4}\right)$, where $\mathrm{H}_{3} \mathrm{Imdc}=$ imidazole-4,5-dicarboxylic acid and bipy=2,2 ${ }^{\prime}$ bipyridine, have been synthesized and characterized using standard analytical and spectroscopic techniques [17]. The X-ray crystal structures of the ruthenium (II) complexes, [(bipy) $\left.\mathrm{Ru}\left(\mathrm{H}_{2} \mathrm{IMDC}\right)\right]\left(\mathrm{ClO}_{4}\right)$ and its corresponding $\mathrm{N}-\mathrm{H}$ deprotonated form [(bipy) $\left.{ }_{2} \mathrm{Ru}(\mathrm{HIMDC})\right]$ have been determined. Both of the metalloreceptors act as sensors for $\mathrm{F}^{-}$, $\mathrm{AcO}^{-}$and $\mathrm{H}_{2} \mathrm{PO}_{4}^{-}$anions. Although at relatively lower concentration of anions, the 1: $1 \mathrm{H}$-bonded adduct is formed, in the presence of excess of anions, deprotonation of the imidazole $\mathrm{N}-\mathrm{H}$ fragment occurs and is accompanied by distinct change of colour [17].

\section{Polyhedral metal center of cobalt and manganese mixed Li- gand complexes of imidazoledicarboxylates}

A new 3D metal-organic framework of $\left\{\left[\mathrm{Co}_{3}(\text { IDC })_{2}(\text { bipy })_{2}(\text { py })_{2}\right] \cdot 7 \mathrm{H}_{2} \mathrm{O}\right\} \mathrm{n}$ was obtained by the hydrothermal reaction of $\mathrm{Co}\left(\mathrm{NO}_{3}\right)_{2} \cdot 6 \mathrm{H}_{2} \mathrm{O}$, imidazole-4,5-dicarboxylic acid ( $\left.\mathrm{H}_{3} \mathrm{IDC}\right)$, 4,4'-bipyridine (bipy), and pyridine (py), and structurally characterized by elemental analysis, infrared spectroscopy, thermal gravimetric analysis, and single-crystal X-ray diffraction. X-ray diffraction crystal structural analysis reveals that it crystallizes in orthorhombic system, space group were also reported [25]. A novel three-dimensional coordination polymer $\left[\mathrm{Mn}_{3}(\mathrm{IMDC})_{2}\left(\mathrm{H}_{2} \mathrm{O}\right)_{4}\right] \quad(\mathrm{IMDC}=4,5-$ imidazoledicarboxylate), consisting of $\left[\mathrm{Mn}_{2}(\mathrm{IMDC})_{2}\left(\mathrm{H}_{2} \mathrm{O}\right)_{2}\right]$ layers and $\left[\mathrm{Mn}\left(\mathrm{H}_{2} \mathrm{O}\right)_{2}\right]$ pillars, was synthesized hydrothermally and characterized by IR spectroscopy, elemental analysis, TGA, and magnetic measurements. It is the first example of a 3D framework containing 4,5-imidazoledicarboxylate in the family of manganese complexes. Generally, the overall coordination ability of multidentate 4, 5-imidazodicarboxylic acid towards divalent metal ion/atom, where ' $\mathrm{M}$ '-divalent ion(s) or metal cation.

\section{Conclusion}

4, 5-Imidazoledicarboxylic acid moiety have been most frequently studied, many of its analogs are active against various pathological conditions, their potential of coordination with metals and supramolecular structure which are discussed in brief in this article. 4, 5-Imidazoledicarboxylic acid is an entity which has interesting physical and chemical properties, in the present article focus lies on analysis of these properties which in turn may be exploited for different, structural chemistry, which are services for different pharmacological activities, like compounds having a 3,4,5-trimethoxyphenyl ring linked to either $\mathrm{N}-1$ or $\mathrm{C}-4$ position of the imidazole entity gave an interesting profile of cytotoxicity with specific activity against leukemia cell lines, combination of indole-imidazole compounds formed One of the other potential activities which are studied in this article is coordination site: flexibility of 4,5-Imidazoledicarboxylic acid derivatives in the formation of metal-organic framework believed to be potent for any sort of imidazole nature. The coordination site and donor ability of, multidentate $\mathrm{H}_{3}$ imdc is the key backbone formation of ligand complexes. Study is done and review in regards to develop Imidazoledicarboxylic acid substituents having both alkyl and carboxylic group refers the interest of research and scientist towards synthesizes, application and characterization of $\mathrm{H}_{3}$ imdc complexes. Thus can say imidazole is a moiety which had been exploited in the past years for synthesizing various compounds having diverse pharmacological activities, and still it can be further utilized for future prospective against various Metalorganic framework conditions and other uses. 


\section{Acknowledgements}

The author this paper like grateful to Adigrat University, Department of Chemistry for creating a good educational environment.

\section{References}

1. Grimmett MR, Hornton BR (1967) Heteroaromatic Nitrogen compounds the azoles.

2. Sethi A (2003) Systematic laboratory experiments in organic chemistry. pp: 763-764.

3. Ross MG (1997) Imidazole and benzimidazole synthesis. Chemical Education Today 76: 288

4. Katritzky AR, Boulton AJ (1992) Advances in heterocyclic chemistry. In: Eckstein Z, Urbanski T (eds.), Chemical Faculty, Warsaw Institute of Technology, Warsaw, Poland 23: 1-33

5. Hofmann K (1953) The chemistry of heterocyclic compounds, imidazole and its derivatives.

6. Bhatnagar A(2011)AReview on Imidazole Their Chemistry and Pharmacological Potentials. Int J Pharm Tech Res 3: 268-282.

7. Yasuda N, Iwagami H, Nakanishi E (1983) Synthesis and Antibacterial activity of 6-and 7-[2-(5-carboxyimidazole-4-carboxamido) phenyl acetamido-pencillin and cephalosporin. J Antibiotics 36: 242-249.

8. Conley RT, James JK, Subrata G (1971) Mechanism of Thermal Oxidation of the Benzimidazole System, p: 71.

9. Yasuda N, Yokosuka CE (2010) Imidazole dicarboxylic acid substituted cephalosporin derivatives.

10. Rong Z, Chang J, Zhuang Q (2011) Two cobalt (II) complexes based on 2-propyl-4, 5-imidazoledicarboxylic acid syntheses, crystal structures and properties. J Coordination Chemistry 64: 1054-1062.

11. Xu LX, Tang SYN (2010) Three New Supramolecular Complexes Based on 2-Propyl-1H-imidazole-4, 5-dicarboxylate: Synthesis, Structures and Properties. Z Anorg Allg Chem 636: 2481-2486.

12. Synder HR, Handrick RG (1955) Books of Organic Syntheses.

13. Wang S, Zhang L, Guanghua L (2010) Assembly of two 3D metal-organic frameworks from Cd (II) and 4,5-imidaziledicarboxylic acid or 2-ethyl-4,5imidazoledicarbixylic acid.
14. Li Z, Guo L, Zhang F (2010) Synthesis and Reactivity in Inorganic, MetalOrganic and Nano-Metal Chemistry. Inorganic and Nano-metal Chemistry 40 734-738.

15. Guang S, Yan G, Gang X (2010) Hydrothermal synthesis, structure, and photoluminescence of four complexes based on $1 \mathrm{H}$-imidazole-4,5-dicarboxylate or $1 \mathrm{H}$-imidazole-2-carboxylate ligands. Journal of Coordination Chemistry 63 : 4188-4200.

16. Das S, Debasish S, Chanchal B (2010) Ru (II) and Os (II) mixed-chelates derived from imidazole-4, 5-dicarboxylic acid and 2,2-bipyridine as colorimetric sensors for anions: synthesis, characterization, and binding studies. J Royal Society of Chemistry Dalton Trans 39: 4162-4169.

17. Feng SJ, Sha R, Zhou T (2010) Three new coordination complexes based on 2-methyl-4, 5-imidazoledicarboxylic acid varying from zero- to twodimensionality. J Coordination Chemistry 63: 4201-4214.

18. Wang WY, Yang ZL, Cheng J (2011) 2-Phenyl-4, 5-imidazole dicarboxylatebased metal-organic frameworks assemled under hydro (solvo) thermal conditions. Cryst Eng comm 13: 4895-4902.

19. Qin Y, Wei Y, Rong J (2009) Two cobalt (II) coordination polymers $\left[\mathrm{Co}_{2}\left(\mathrm{H}_{2} \mathrm{O}\right)\right.$ $\left.{ }_{4}(\mathrm{Hbidc})_{2}\right] \mathrm{n}$ and [Co (Hbidc)]n: - syntheses, crystal structures, and magnetic properties. Cryst Eng Comm 11: 1054-1060.

20. Partha M, Srinivasan N (2005) Pyridine- and Imidazoledicarboxylates of Zinc: Hydrothermal Synthesis, Structure, and Properties. Eur J Inorg Chem 11: $2156-2163$.

21. Lin W, Evans OR, Xiong RG (1998) Supramolecular Engineering of Chiral and Acentric 2D Networks. Synthesis, Structures, and Second-Order Nonlinear Optical Properties of Bis(nicotinato)zinc and Bis\{3-[2-(4-pyridyl) ethenyl] benzoato\}cadmium. J Am Chem Soc 120: 13272-13273.

22. Evans OR, Xiong RG, Wang Z (1999) Crystal engineering of acentric diamondoid metal-organic coordination networks. Angew Chem 38: 536-538.

23. Lin W, Ma L, Evans OR (2000) NLO-active zinc(II) and cadmium(II) coordination networks with 8-fold diamondoid structures. Chem Commun 2: 2263-2264.

24. Yali S, Xuesong L, Weidong S, Suhua Y (2011) Two Zinc(II) Supramolecules Constructed from Imidazole Dicarboxylate: Synthesis, Structures, and Properties. Synthesis and Reactivity in Inorganic, Metal-Organic and NanoMetal Chemistry 41: 356-362.

25. Yuan L, Wen G (2011)A New 3D Layered-pillared Cobalt (II)-organic Framework Constructed by Imidazole-4, 5-dicarboxylic Acid ( $\left.\mathrm{H}_{3} \mathrm{IDC}\right)$ and 4, 4'-Bipyridine (bipy). Chinese J Struct Chem 30: 1207-1213. 